\title{
Postoperative analgesic requirements in patients exposed to positive intraoperative suggestions
}

\author{
T T C McLintock, H Aitken, C F A Downie, G N C Kenny
}

\begin{abstract}
Objective-To establish whether positive suggestions given to a patient under general anaesthesia reduce postoperative pain and analgesic requirements.

Design-Prospective double blind randomised study.

Setting-Operating theatre and gynaecology ward of a teaching hospital.

Patients-63 Woman undergoing elective abdominal hysterectomy were randomised to be played either a tape of positive suggestions or a blank tape during the operation through a personal stereo system.
\end{abstract}

Interventions-Three women were withdrawn from the study. Anaesthesia was standardised for all of the women. Postoperative analgesia was provided through a patient controlled analgesia system for the first 24 hours. Pain scores were recorded every six hours.

Main outcome measures-Morphine consumption over the first 24 hours after the operation; pain scores.

Results-Mean morphine requirements were $51.0 \mathrm{mg}$ ( $95 \%$ confidence interval 42.1 to $60.0 \mathrm{mg}$ in the women played positive suggestions; and $65.7 \mathrm{mg}$ $(55.6$ to $75.7 \mathrm{mg}$ ) in those played a blank tape. The point estimate (95\% confidence interval) for the difference of means was $14.6 \mathrm{mg}(22.4 \%)(1.9(2.9 \%)$ to $27.3 \mathrm{mg}(41.6 \%))(\mathrm{p}=0.028)$. Pain scores were similar in the two groups.

Conclusion-Positive intraoperative suggestions seem to have a significant effect in reducing patients' morphine requirements in the early postoperative period.

\section{Introduction}

In an uncontrolled study in 1965 Levinson showed that apparently well anaesthetised patients have some memory for sounds occurring during the operation.' Since then properly designed double blind studies have confirmed, for the most part, that some form of unconscious perception can occur in patients undergoing adequate general anaesthesia. ${ }^{2.7}$ Two studies by the same workers have, however, produced conflicting results. ${ }^{56}$ Most of the studies were based on the assessment of a non-verbal response (such as word recognition) to the intraoperative sounds. More recently the possible beneficial effect on patient outcome of positive intraoperative suggestions has been examined. One group of workers found a reduction in postoperative morbidity, which was confined to more elderly patients, ${ }^{5}$ and another group found a reduction in various postoperative complications and in hospital stay in those exposed to positive suggestions. ${ }^{8}$ In this study there was evidence of a reduction in analgesic requirements in such patients, but this was not significant. ${ }^{8}$

Assessment of analgesic requirements based on requests for intramuscular opiates to be given by nursing staff is a crude and probably unreliable measure of the patient's real needs. ${ }^{9}$ Because of shortages of nursing staff or inappropriate prescription of intermittent intramuscular opioids many patients do not receive optimal analgesia. ${ }^{10}$ Patient controlled analgesia allows patients to titrate their analgesic requirements against their pain and removes the effect of observer bias when analgesic requirements are studied. " Because patient controlled analgesia allows the patient virtually unrestricted access to analgesia it is a more sensitive way of assessing differences in analgesic requirements between two groups of patients than an intermittent intramuscular regimen. ${ }^{12} \mathrm{We}$ examined the possibility that requirements for patient controlled analgesia could be reduced by positive intraoperative suggestions on an audio tape played through a personal stereo system.

\section{Patients and methods}

The study was approved by the hospital ethics committee and informed written consent was obtained. All patients were grade 1 or grade 2 according to the American Society of Anesthesiologists' classification ${ }^{13}$ -that is, they were normal healthy patients or had only a mild systemic disease. Sixty three women scheduled to undergo elective abdominal hysterectomy by Pfannenstiel's incision were entered into the study. Those with evidence of renal or hepatic impairment were excluded, as were those who had received narcotic analgesics in the preceding 48 hours. Women known to misuse drugs or alcohol were also excluded. Patients were then allocated randomly to two groups: those who would be played a tape containing positive suggestions during the operation and those who would be played a blank tape. Women in both groups were premedicated with temazepam, and anaesthesia, which was standardised for all patients, was induced with thiopentone $4 \mathrm{mg} / \mathrm{kg}$; neuromuscular blockade was produced with vecuronium; analgesia was provided by morphine $0.15 \mathrm{mg} / \mathrm{kg}$; and anaesthesia was maintained with nitrous oxide with oxygen $66 \%$ and enflurane $0 \cdot 8-1 \cdot 5 \%$. Neuromuscular blockade was reversed at the end of the procedure with atropine and neostigmine.

Audio tapes were played to the patients through a personal stereo system of the Walkman type with an autoreverse facility. The tape player had a Dolby noise reduction system to reduce tape hiss. The message in the suggestion tape lasted about 15 minutes. It was started at induction and stopped at the time of extubation and was repeated continuously during the operation. The suggestions consisted of statements such as: "Everything is going very well, we're very pleased with your progress"; "You feel warm and comfortable, calm, and relaxed"; "Any pain that you feel after the operation will not concern you." The tapes were visually indistinguishable, and none of the observers were aware of which tape the patient had been played.

On arrival in the recovery room the patients were connected to a patient controlled analgesia system ${ }^{14}$ that delivered intravenous bolus doses of morphine through a valved $\mathrm{Y}$ connecter. ${ }^{15}$ The bolus size was set at $0.02 \mathrm{mg} / \mathrm{kg}$ and the lockout time was three
Correspondence to:

Dr McLintock.

BrMed J 1990;301:788-90 
minutes. The maximum dose of morphine allowed was $0.4 \mathrm{mg} / \mathrm{kg}$ in any one hour period and $0.8 \mathrm{mg} / \mathrm{kg}$ in any three hour period-that is, 20 and 40 bolus doses respectively. A record of the time of each bolus dose was automatically recorded on computer disc for later analysis. The patients received different audible signals to indicate whether a dose request had been successful or not. Pain scores were recorded on a $100 \mathrm{~mm}$ linear analogue scale ${ }^{16}$ by the patient at six, 12 , 18 , and 24 hours postoperatively. At 24 hours the patient was also asked whether she had any recall of hearing anything from induction to awakening in the recovery area. Episodes of nausea that required treatment and vomiting were also recorded. Statistical analysis was performed by using the Minitab statistics package with Student's $t$ test, the Mann-Whitney U test, and the $\chi^{2}$ test.

\section{Results}

Of the 63 patients enrolled into the study, three were withdrawn: one developed severe pleuritic chest pain early in the postoperative period; one changed her mind about being included in the study; and one was withdrawn because of a breakdown of the patient controlled analgesia system.

Table I gives the patients' demographic details. There were no significant differences in the ages or weights of the patients between the two groups.

Table II shows the morphine requirements over 24 hours after the operation and the incidence of nausea or vomiting. It can be seen that the women who had been played positive suggestions during their operation used $23 \%$ ( $95 \%$ confidence interval $2 \cdot 9 \%$ to $41 \cdot 6 \%$ ) less morphine than those who had been played a blank tape

TABLE I-Mean (95\% confidence interval) age and body weight of women who were played either positive suggestions or blank tape while undergoing hysterectomy

\begin{tabular}{lcc}
\hline & $\begin{array}{c}\text { Women played } \\
\text { positive suggestions } \\
(\mathbf{n}=30)\end{array}$ & $\begin{array}{c}\text { Women played } \\
\text { blank tape } \\
(\mathbf{n}=30)\end{array}$ \\
\hline $\begin{array}{l}\text { Age }(\text { years }) \\
\text { Weight }(\mathrm{kg})\end{array}$ & $\begin{array}{l}40 \cdot 5(37 \text { to } 44) \\
60 \cdot 2(57 \text { to } 63)\end{array}$ & $\begin{array}{l}40 \cdot 8(39 \text { to } 43) \\
62 \cdot 0(59 \text { to } 65)\end{array}$ \\
\hline
\end{tabular}

TABLE II -Mean (95\% confidence interval) morphine requirements over 24 hours and incidence of nausea or vomiting in women who were played either positive suggestions or blank tape while undergoing hysterectomy

\begin{tabular}{lllc}
\hline & $\begin{array}{c}\text { Women played } \\
\text { positive suggestions } \\
(\mathbf{n}=30)\end{array}$ & $\begin{array}{c}\text { Women played } \\
\text { blank tape } \\
\text { (n=30) }\end{array}$ & $\begin{array}{c}\text { 95\% Confidence } \\
\text { interval for difference } \\
\text { of means }\end{array}$ \\
\hline $\begin{array}{l}\text { Morphine requirement }(\mathrm{mg}) \\
\text { No with nausea/vomiting }\end{array}$ & $\begin{array}{l}51 \cdot 0(42 \cdot 1 \text { to } 60 \cdot 0) \\
16\end{array}$ & $\begin{array}{l}65 \cdot 7(55 \cdot 6 \text { to } 75 \cdot 7) \\
13\end{array}$ & $1 \cdot 9$ to $27 \cdot 3^{\star}$ \\
\hline
\end{tabular}

${ }^{\star} \mathrm{p}=0 \cdot 028 ; t=2 \cdot 26 ; \mathrm{df}=57 \cdot 3$.

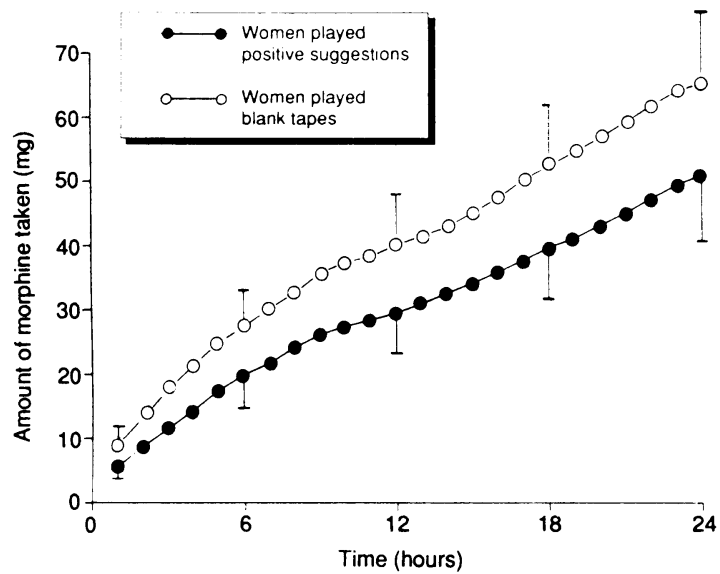

Cumulative mean hourly consumption of morphine in women who were played either positive suggestions or blank tape while undergoing hysterectomies. (Bars indicate the upper or lower limits of the $95 \%$ confidence intervals) $(\mathrm{p}=0 \cdot 028 ; t=2 \cdot 26 ; \mathrm{df}=57 \cdot 3)$. The figure shows the cumulative morphine consumption over 24 hours. The women who had been played positive suggestions showed a reduction in their morphine consumption compared with those who had been played a blank tape even after the first hour, and this difference gradually increased over the 24 hours. Table III gives the pain scores: there were no significant differences between the two groups. No patients could recall hearing any sounds or having any dreams from the time of induction to recovery.

TABLE III-Median (range) pain scores ( $\mathrm{mm}$ ) on linear analogue scale in women played either positive suggestions or blank tape while undergoing hysterectomy

\begin{tabular}{lccc}
\hline $\begin{array}{c}\text { No of hours } \\
\text { postoperatively }\end{array}$ & $\begin{array}{c}\text { Women played } \\
\text { positive } \\
\text { suggestions }\end{array}$ & $\begin{array}{c}\text { Women played } \\
\text { blank tape }\end{array}$ & $\begin{array}{c}95 \% \text { Confidence } \\
\text { interval for } \\
\text { median } \\
\text { difference }\end{array}$ \\
\hline 6 & $27 \cdot 5(1-57)$ & $41 \cdot 5(0-83)$ & -21 to 3 \\
12 & $22 \cdot 5(0-65)$ & $23(2-76)$ & -15 to 6 \\
18 & $23(0-64)$ & $23 \cdot 5(0-67)$ & -12 to 8 \\
24 & $20(0-81)$ & $17(0-91)$ & -16 to 6 \\
\hline
\end{tabular}

\section{Discussion}

In assessing the effect of positive suggestions on analgesic requirements it is important to exclude any effects of observer bias. Patient controlled analgesia allows patients to have analgesia whenever they require it whereas there may be considerable delay when a request is made for intramuscular analgesia because of ward procedures and shortages of appropriately trained staff. As well as this medical staff may prescribe inappropriate doses for an individual patient. As a result many patients receiving an intermittent intramuscular regimen will receive less than ideal analgesia. Therefore, analgesic requirements based on demands made from a patient controlled analgesia system should be more representative of the patient's real needs. An additional benefit is that patients often comment that they feel more confident with patient controlled analgesia because they are in control of the management of their pain.

If pain perception is reduced by positive intraoperative suggestions patients might use less morphine from a patient controlled analgesia system or their pain scores might be reduced, or both. In this study the patients who were exposed to positive suggestions showed a reduction of $23 \%$ in their morphine requirements in the first 24 hours postoperatively. There were no significant differences in pain scores between those who were played positive suggestions and those who were played a blank tape, although there was a nonsignificant reduction in the median score in those exposed to positive suggestions at six hours. Interestingly, the incidence of nausea or vomiting was the same, at about $50 \%$. Although the tape did not specifically mention nausea or vomiting, it could be expected that the general positive suggestions on the tape would have reduced feelings of nausea.

This is the second study to show that positive intraoperative suggestions can have a beneficial effect on patients undergoing hysterectomy. The first study found a reduction in intramuscular analgesic requirements, but this difference was not significant. ${ }^{8}$ Our study is the first to use patient controlled analgesia as an unbiased assessment of morphine requirements, and hence the efficacy of positive intraoperative suggestions. The types of suggestions used in these two studies were different, and it may well be that the ideal form of positive suggestions has yet to be found. It has also been shown that negative suggestions or events can have an adverse effect on patient wellbeing. ${ }^{23}$ We recommend, therefore, that more patients should be 
offered exposure to positive suggestions during general anaesthesia. This would give patients the beneficial effect of the positive suggestions and protect them from the negative effects of "hearing" adverse or negative comments.

1 Levinson B. States of awareness during general anaesthesia. $\mathrm{Br} \mathcal{O}$ Anaesth $1965 ; 31: 544-6$

Goldman L. Information processing under general anaesthesia: a review. $\mathcal{F}$ Soc Med 1988:81:224-7.

3 Anonymous. Advertising during anaesthesia? [Editorial]. Lancet 1986;ii: $1019-20$.

4 Jones J, Konieczko K. Hearing and memory in anaesthetised patients. Br Med f 1986;292:1291-3.

5 Bonke B, Schmitz P, Verhage F, Zwaveling A. Clinical study of so-called unconscious perception during general anaesthesia. $\mathrm{Br} \mathcal{J}$ Anaesth 1986;58: 957-64.

6 Boeke S, Bonke B, Bouwhuis-Hoogerwerf M, Bovill J, Zwaveling A. Effects of sounds presented during general anaesthesia on postoperative course. $\mathrm{Br} \mathcal{J}$ Anaesth 1988;60:697-702.
7 Bennet H, Davis $\mathrm{H}$, Giannini J. Non-verbal response to intraoperative conversation. Br I Anaesth 1985:57:174-9.

8 Evans C, Richardson P. Improved recovery and reduced postoperative stay after therapeutic suggestions during general anaesthesia. Lancet 1988;ii: after ther.

9 Dodson $M$. A review of the methods for relief of postoperative pain. Ann R Coll Surg Engl 1982;64:324-7.

10 Nayman J. Measurement and control of postoperative pain. Ann R Coll Surg Engl 1979;61:419-26.

11 Sechzer P. Objective measurement of pain. Anesthesiology 1968;29:209-10. 12 McLintock T, Hodsman N. Patient-controlled analgesia: a review. Intensive Care Nursing 1987;3:8-13.

13 American Society of Anesthesiologists. New classification of physical status. Anesthesiology 1963;24:111.

14 Gillies G, Kenny G, McArdle C. A standard microcomputer linked to a volume-controlled infusion pump for patient-controlled analgesia. $\mathcal{J}$ Med Eng Technol 1986;10:55-7.

15 Rosen M, Williams B. The valved-Y-Cardiff connector (VYCCon). Anaesthesia 1979:34:882-4.

16 Huskisson E. Measurement of pain. Lancet 1974;ii:1127-31.

Melanie CDavies, Margaret LLHall, Howard S Jacobs

Abstract

Objective-To examine the impact of amenorrhoea on bone mineral density in women of reproductive age.

Design-Cross sectional study of 200 amenorrhoeic women compared with normally menstruating controls.

Setting-Teaching hospital outpatient clinic specialising in reproductive medicine.

Subjects -200 Women aged $16-40$ with a past or current history of amenorrhoea from various causes and of a median duration of three years, and a control group of 57 age matched normal volunteers with no history of menstrual disorder.

Main outcome measure-Bone mineral density in the lumbar spine (L1-L4) as measured by dual energy $x$ ray absorptiometry.

Results-The amenorrhoeic group showed a mean reduction in bone mineral density of $15 \%$ (95\% confidence interval $12 \%$ to $18 \%$ ) as compared with controls (mean bone mineral density 0.89 (SD $0.12) \mathrm{g} / \mathrm{cm}^{2} v 1.05(0.09) \mathrm{g} / \mathrm{cm}^{2}$ in controls). Bone loss was related to the duration of amenorrhoea and the severity of oestrogen deficiency rather than to the underlying diagnosis. Patients with a history of fracture had significantly lower bone density than those without a history of fracture. Ten patients had suffered an apparently atraumatic fracture.

Conclusions-Amenorrhoea in young women should be investigated and treated to prevent bone mineral loss. Menopausal women with a past history of amenorrhoea should be considered to be at high risk of osteoporosis.

Middlesex Hospital, London

Melanie C Davies, MRCOG, research fellow, department of reproductive endocrinology Margaret L Hall, MRCP, lecturer in nuclear medicine Howard S Jacobs, FRCP, professor of reproductive endocrinology

Correspondenceto: Dr M C Davies, Cobbold Laboratories, Middlesex Hospital, London] WIN 8AA.
Stress fractures occur in amenorrhoeic runners with low bone mineral density ${ }^{7}$ and in ballet dancers with prolonged lack of oestrogen. ${ }^{8}$ Appreciable loss of bone has been recorded in women with hyperprolactinaemic amenorrhoea. ${ }^{910}$ Cann et al found in a series of 38 amenorrhoeic women aged 16-49 that spinal bone mass was reduced when assessed by quantitative computed tomography. ${ }^{11}$

Amenorrhoea is common in women of reproductive age with a reported prevalence of at least $2 \% \cdot{ }^{1213}$ Hence any effect on bone mass would have important consequences by predisposing these women to osteoporosis in later life.

Other studies have generally been confined to a single diagnostic group and have been limited by small numbers and comparatively inaccurate techniques of measurement. Measurements have often been confined to peripheral cortical bone whereas loss of trabecular bone is of greater clinical importance. Changes in the lumbar spine seem to be a sensitive indicator of bone loss. ${ }^{14}$ We report on a large series of young women with amenorrhoea who were subjected to bone densitometry of the lumbar spine by quantitative digital radiography, which has greater precision than other techniques.

\section{Subjects and methods}

The study population consisted of 200 white women of reproductive age ( $16-40$; mean $27 \cdot 8$ years) who had a past or current history of amenorrhoea (defined as absence of menstruation for at least six months). They were an unselected consecutive series of outpatients who attended the reproductive endocrinology clinics at the Middlesex Hospital and Soho Hospital for Women over 18 months. During this period half of all new referrals to the clinics came direct from general practitioners.

The duration of amenorrhoea ranged from six months to 24 years (median 3.0 years). Forty seven patients had primary and 153 secondary amenorrhoea. The cause of amenorrhoea was determined by history, examination, serum hormone estimations, and imaging techniques as appropriate. ${ }^{15}$ The diagnostic categories with the largest numbers of patients were weight related amenorrhoea $(n=49)$ and premature ovarian failure $(n=48)$. Twenty two patients had hyperprolactinaemia, 18 polycystic ovarian disease, 17 isolated hypogonadotrophic hypogonadism, and 18 